\title{
Measurement of Current due to Space Charge Present in PVC Sheaths after Aging under AC Sinusoidal High Voltage by the Thermal Wave Method
}

\author{
Youcef ZEBBOUDJ, Abdelkrim LAIFAOUI, Hakim AIT SAID and Jean Michel REBOUL
}

\begin{abstract}
Several techniques exist to characterize the presence of remanent polarization and / or space charge in an insulating material. Among them which may be mentioned thermal methods such as the Thermal Wave Method (TWM). Among the most widely used polymers in electrical insulation, we find the polychloride vinyl $(P V C)$. In this work, we describe the characterization of PVC sheaths to improving the reliability of power transmission cables. We set the objective to adapt the TWM for space charges measures in this material and under this cylindrical form. The study concerns a few samples of PVC sheaths, part of which has undergone aging until 4250h under alternating voltage of $20 \mathrm{kV}$ sinusoidal AC voltage in the electrical engineering laboratory of Bejaia (LGEB). Also we have another lot of samples in new condition for comparison. The space charge measurements were made at LUSAC in Cherbourg. After presenting the specific banc measurement of MOT for this type of samples, we present the first current measurements on samples aged under tension between 500 and 4250 hours. The first analyzes show that the current of MOT increase gradually but irregularly depending on the aging time.
\end{abstract}

Keywords: Thermal Wave Method; Space charge, current of MOT, PVC sheaths, Electrical aging, Heat front, Thermal gradient.

\section{Introduction}

In the solid insulators subjected to high electrical constraints, a number of poorly known mechanisms often lead to the establishment of a space charge distribution [1] that breaks the electrical neutrality of certain regions of the insulator. This situation persists or progresses slowly, even after switching off the external electrical constraint which gave it birth. Space charge accumulated in these areas has the effect of introducing a non-uniform distribution of the electric field enhances the degradation and aging of the material and reduces the lifetime of devices working under high voltage such as cables and capacitors [2].

The space charges are electric charges not cleared and / or gradients of dipoles oriented in a preferential direction, which are divided in the volume of an insulator. Their appearance

Youcef ZEBBOUDJ, Abdelkrim LAIFAOUI, Hakim AIT SAID Laboratoire de Génie Electrique de Bejaia - Université de Bejaia Algeria

Jean Michel REBOUL

Laboratoire Universitaire des Sciences Appliquées de Cherbourg-Octeville France intervenes as soon the elaboration of the material and inevitably continues during use under the effect of applied constraints (electric field, electrical and / or thermal aging, exposure to ionizing radiation ...). The accumulation of these charges in certain zones of the insulator distorts the external electric field applied when the material is under voltage and has for effect, a risk to prime the electrical breakdown. Several techniques exist to characterize the presence of these charges in the volume of the insulator [3]. Among these methods, we are interested especially in that whose principle uses a variation of temperature and can be described by "thermal methods". If the temperature variation is important during measuring and if it changes the electrical state of the sample by removing all or part of the charges stored, the method is said "destructive". In contrast, when the temperature variations are weak or do not leave the domain of electrical stability of the sample, the method is said "non-destructive" [4-6]. This latter case is interesting because it allows the repetition and verification of the reproducibility of measurements. It is also suitable for follow-up studies of the evolution of a sample over time.

\section{Thermal Wave Method}

The so-called "thermal wave" method (MOT in french) has been developed in Montpellier since twenty years ago. This method is a reference method for measuring space charge especially in cables [6-12]. It is based on the diffusion of a heat front applied to one side of the insulator and on the nonuniform dilatation that results. This generates a current due to the local movement of space charges in the material during dilatation (or contraction). This method has proven extremely efficient for samples of planar geometry [13] or cylindrical [14] and for a wide range of thicknesses ranging from hundreds of microns to a few centimeters. A numerical method of deconvolution that includes the experimental currents and the temperature distribution in the sample during the measurement permits to estimate the charge density [15].

\section{Samples}

The study was conducted on 15 samples of soft PVC sheaths (length of $80 \mathrm{~cm}$, internal diameter of $4 \mathrm{~mm}$ and thickness of $1.5 \mathrm{~mm}$ ). The samples were cut from a roll of duct of $100 \mathrm{~m}$ 
Proc. of the Third Intl. Conf. on Advances in Mechanical and Automation Engineering - MAE 2015. Copyright $($ Institute of Research Engineers and Doctors, USA .All rights reserved.

ISBN: 978-1-63248-080-4 doi: 10.15224/ 978-1-63248-080-4-115

provided by the Electro-Industrial company (ENEL Azazga, Algeria). Some of these samples have undergone aging electrical at laboratory temperature for a period ranging from 500 to 4000 hours under AC voltage of $20 \mathrm{kV} \mathrm{50Hz}$. Another part of these samples is stored in new condition for comparison. To avoid breakdowns of air by circumvention, only a length of $10 \mathrm{~cm}$, corresponding to the middle of the sheath has been polarized.

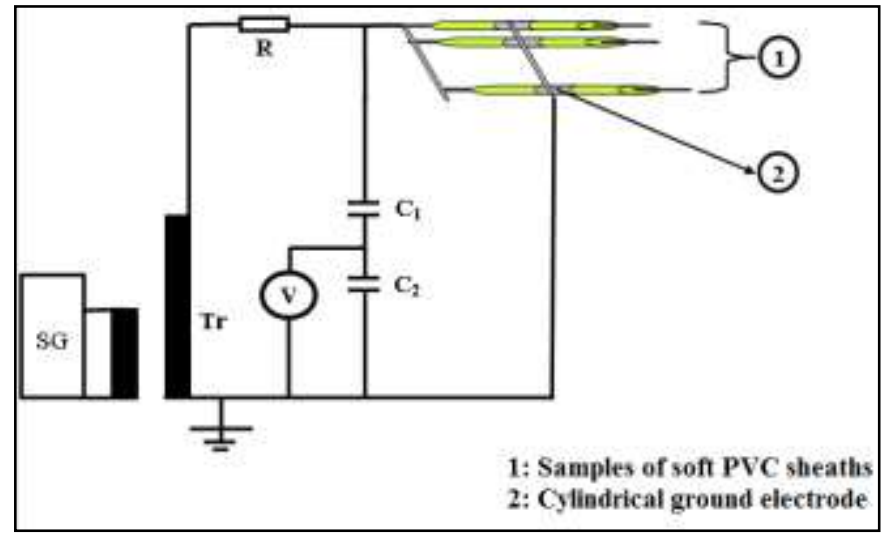

Figure 1. Device aging test

The aging device comprising the following elements described in Figure 1:

- SG : A voltage source with several speeds of rise of the ramp.

- $\quad$ Tr : HT $100 \mathrm{kV}$ transformer can output a voltage from 0 to $100 \mathrm{kV}$ for tests under AC voltage.

- A capacitive voltage divider $\left(C_{0}=0,1 \mu F\right.$ and $\left.C_{u}=41,4 \mu F\right)$.

- A peak voltmeter $\left(U_{c r}\right)$ AC / DC type MU11, digital display for measuring, according to the electrical circuit, high AC voltages, or continuous.

- A protective resistor $\mathrm{R}=106 \mathrm{k} \Omega$ limiting current.

- A built used for the whole test tube and electrodes.

- A stainless steel electrode inserted within the sheath serving as a high voltage electrode.

- The cylindrical ground electrode of stainless Aluminum wound on the outer part of the sheath.

- A protective cage.

The tests consist in polarizing under alternating voltage of $20 \mathrm{kV}$ AC AC $50 \mathrm{~Hz}$, samples of sheaths for an increasingly long period. Aging takes place in the open air and the ambient temperature of the laboratory.

\section{Experimental Implementation}

For flat samples, the thermal front, echelon shaped, is conventionally obtained by supplying hot or cold liquid in hydraulic radiator which also serves as an electrode. The sample is initially at ambient temperature in contact with this one and is subjected to a thermal shock on one of its faces. The measurement takes place during the change in temperature of the sample which also corresponds to the progression of a temperature front through its thickness. The French name of the method originates from this phenomenon. The theory shows that the distribution of space charge in the sample causes an experimental current that depends on speed progression of the thermal front passing through the sample. Experimentally we seek to maximize this parameter to obtain even more detectable because measuring signals can be very weak. $n$ practice the values attained locally are of the order of $\pm 10^{\circ} \mathrm{C} / \mathrm{s}$. In case of thermal shock causing heating of the sample, the harmful temperature can be reached rapidly, we prefer therefore a thermal shock producing cooling.

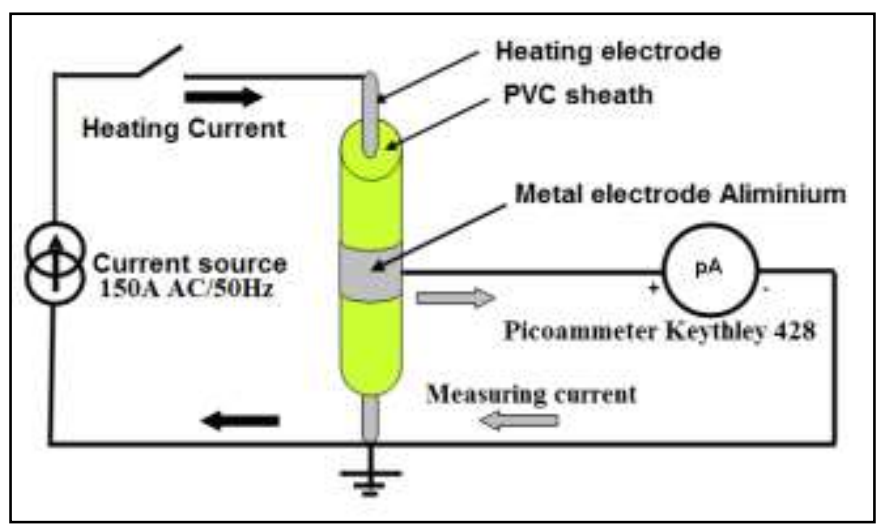

Figure 2. Measuring device MOT

However, for our samples of cylindrical shape, we have developed and perfected a radiator that heats up the sample a few degrees above ambient temperature. A rapid heating is obtained by the Joule effect using a radiator inserted inside of the sheath (Figure 2). The heating time is short and limited to maximum $3 \mathrm{~s}$ so that the maximum temperature attained in the heart of the sheath does not degrade the dielectric state of the sample $\left(35^{\circ} \mathrm{C}\right)$. This allows repeated measurements after returning to ambient temperature by natural cooling of the sample. The measurement electrodes are formed on the one hand, by the aluminum adhesive tape bonded to the outside of the sheaths over a length of $10 \mathrm{~cm}$, and by metallic radiator on the other. The assembly forms a cylindrical capacitor whose dielectric is constituted by the sheath to be tested. The current is measured using a picoammeter Keythley 428, and temperature by two fast thermocouples type $\mathrm{K}$, one on the edge of the sheath and the other inside in contact with the heating electrode.

A brief heating current of $150 \mathrm{~A}-50 \mathrm{~Hz} \mathrm{AC}$ is applied to the axial electrode to cause a thermal shock inside the sheath.

One can measure the abrupt rise in temperature inside the sheath caused by the Joule effect of heating electrode (about $15^{\circ} \mathrm{C}$ in 3 seconds at an average speed of rise of $5^{\circ} \mathrm{C} / \mathrm{s}$ ) then 
Proc. of the Third Intl. Conf. on Advances in Mechanical and Automation Engineering - MAE 2015.

Copyright $\odot$ Institute of Research Engineers and Doctors, USA .All rights reserved.

ISBN: 978-1-63248-080-4 doi: 10.15224/ 978-1-63248-080-4-115

slow natural cooling. The temperature measured on the outside of the sheath increases more slowly and attains its maximum 20 seconds after the start of heating. This gives an idea of time of crossing the heat front through the sheath. The sample is then returned to the ambient temperature in order to start a new measurement to confirm the previous results. Given that the sample has not undergone of harmful overheating the measurements are non-destructive and reproducible under these conditions (Figs. 5a and 5b). During the heating phase, the picoammeter saturates due to electromagnetic radiation of heater current and switches to mode"security".

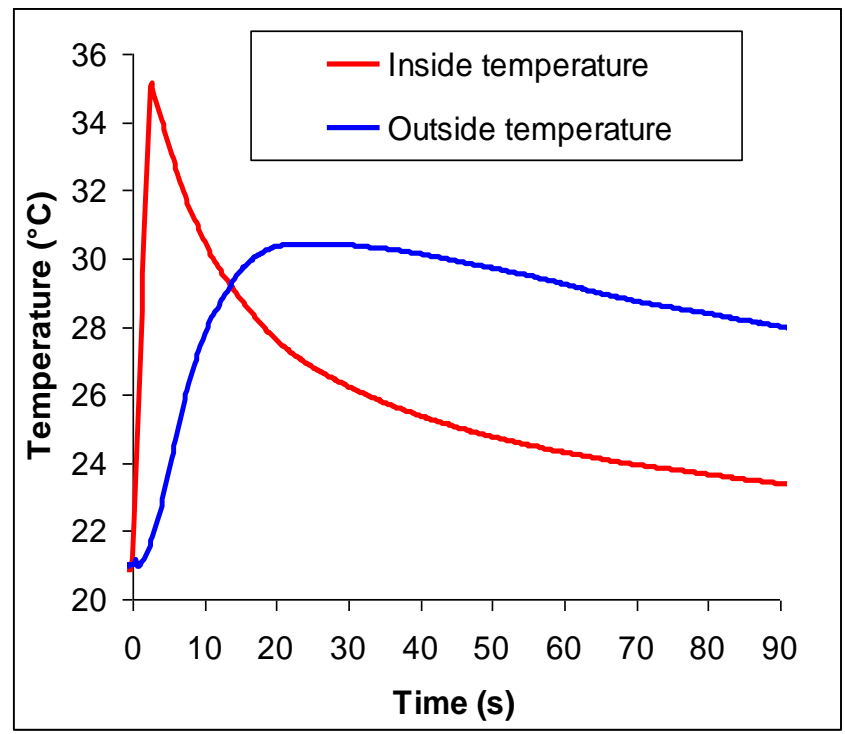

Figure 3a. Temperature graph

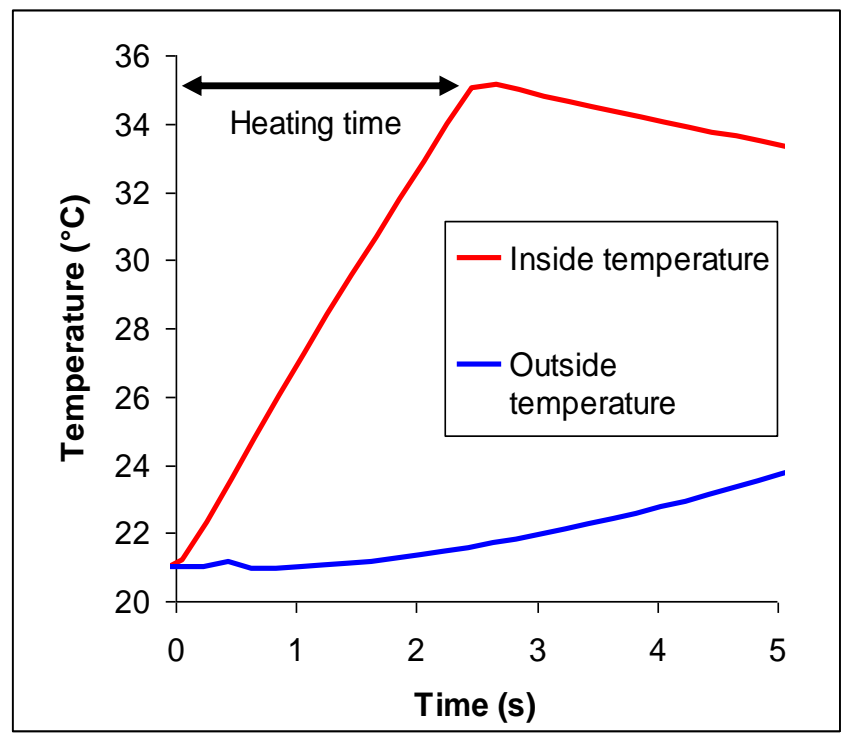

Figure $3 b$. Focus on the first moments for temperature measurements (b)

Although the MOT current theoretically begins from the first moment of heating of the sheath, it did not prove possible to measure it with our means to date. The first three seconds of recording our current MOT corresponding to the generation of heating are not significant. Measuring the experimental current during these moments constitute a margin of undeniable progress.

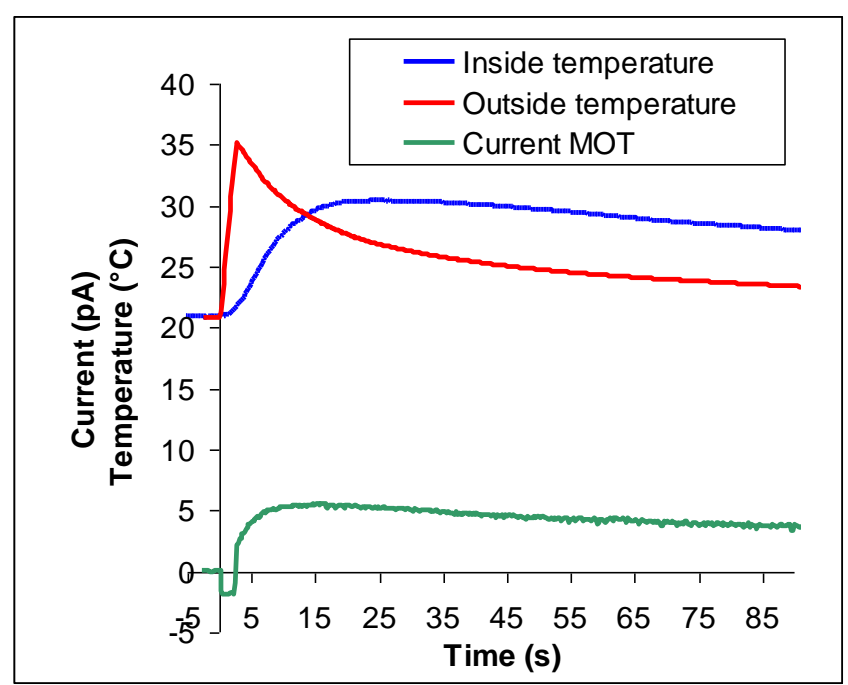

Figure 4. Recording current MOT and temperature of the sheath

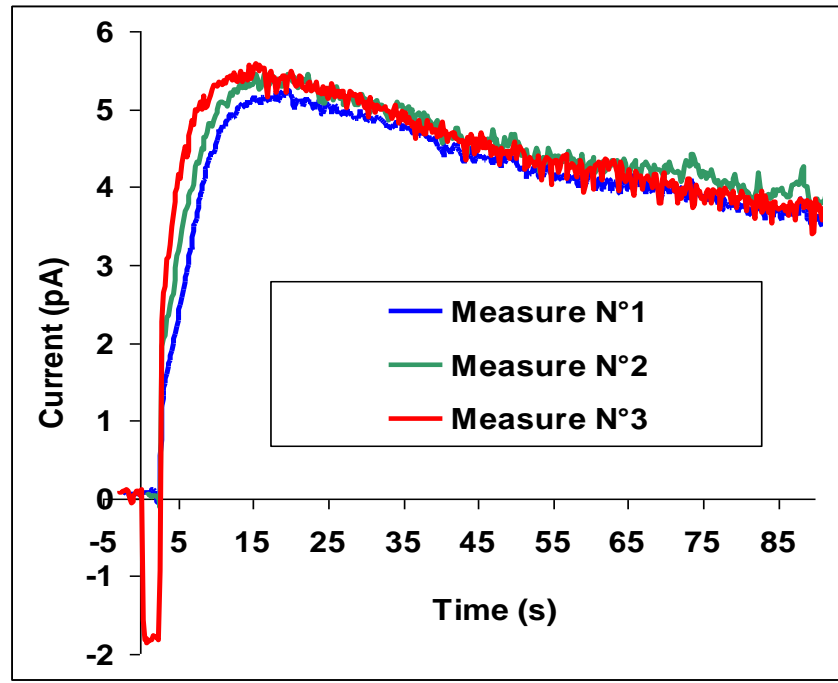

Figure 5a. Repeatability test

Analysis of the curves of the currents, will therefore focus on the second part of measurement corresponding to the phase in which the heating is cut off.

\section{Results And Discussions}

Figures $6 \mathrm{a}$ and $6 \mathrm{~b}$ show the currents measured on the sheaths for different duration of aging. All currents present maxima occurring before that the heat front has completely crossed the sheath, just before the first 20 seconds of recording, then amortized more slowly. The analysis of maxima values gives a quantitative idea on space charge density stored in the sheath.

We observe an increase of current amplitudes with the aging duration. However, we can suspect that the phenomenon of 
Proc. of the Third Intl. Conf. on Advances in Mechanical and Automation Engineering - MAE 2015.

Copyright $\odot$ Institute of Research Engineers and Doctors, USA .All rights reserved.

ISBN: 978-1-63248-080-4 doi: 10.15224/ 978-1-63248-080-4-115

charges installation has several phases. Indeed the increase of current amplitudes is not linear with the aging duration. The current is extremely small on the reference sample but increases abruptly and regularly for ageing from 1500 to $2500 \mathrm{~h}$. From $3000 \mathrm{~h}$, the increase is more straightforward.

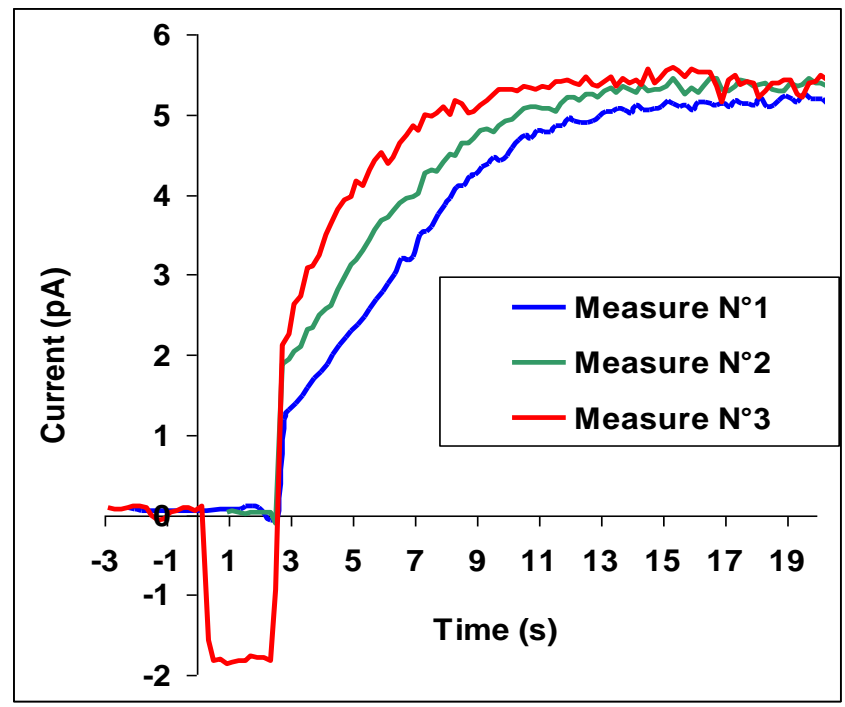

Figure $5 b$. Focus on the first moments for current measurements.

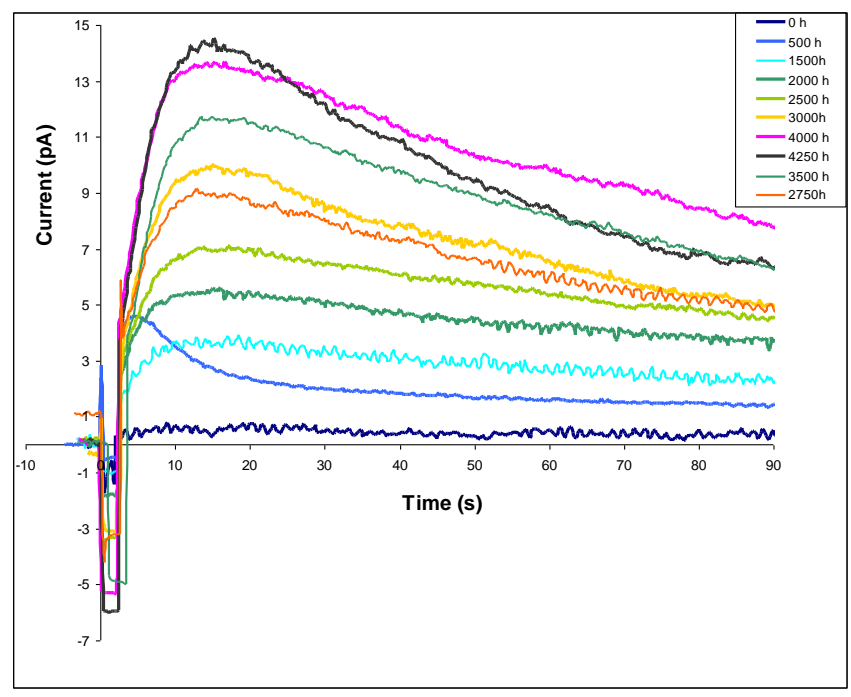

Figure 6a. MOT Currents for different aging times

Finally, the ageing of 4000 and $4250 \mathrm{~h}$ give currents of the same amplitude and the strongest of the serie. This irregular increase reveals an installation of space charge according to a complex phenomenon.

\section{Conclusion}

We have developed a measurement bench of space charges with thermal wave of sheaths of inside diameter of $4 \mathrm{~mm}$ and a thickness of $1.5 \mathrm{~mm}$. A short warm-up is obtained by Joule effect inside the sheath and permits to measure currents associated to space charges in a reproducible manner.

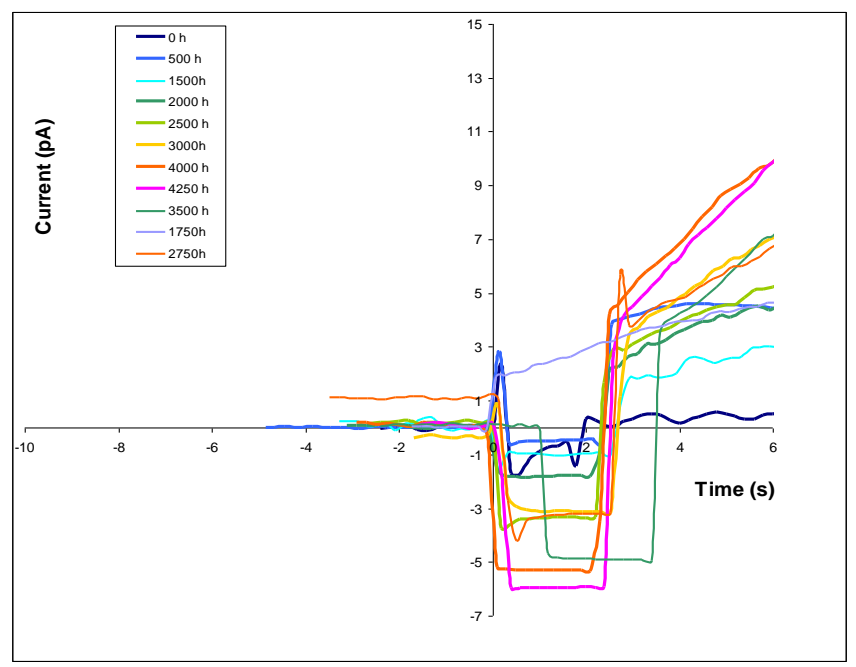

Figure $6 \mathrm{~b}$. Zoom on the first moments for measuring currents of MOT

The study focused on a group of 15 aged PVC sheaths under AC voltage of $20 \mathrm{kV}$ AC $50 \mathrm{~Hz}$ for a period ranging from 500 to 4000 hours. The first results show a progressive increase but irregular of currents associated to space charges with the ageing duration.

\section{References}

[1] Z. Croitoru, "Space Charge in dielectrics", progr. Dielectr. 6 (1965) 102.

[2] A. Toureille, J.P. Reboul, P. Merle, "Détermination des densités de charge d'espace dans les isolants solides par la méthode de l'onde thermique", J. Phys. III, vol 1, p. 111- 123, 1991.

[3] J.M. Reboul, T. Mert, D. Houivet, "Méthodes thermiques pour la caractérisation des diélectriques et isolants électriques", MATERIAUX 2010 - 18-22 octobre 2010 - Nantes, France.

[4] J.M. Reboul, "Mise au point d'une nouvelle méthode à onde thermique alternative pour l'étude des charge d'espace dans les films diélectriques: "Techniques expérimentales et protocole pour le traitement de signal", thèse de doctorat, Université de Caen-Basse Normandie, France, 2000.

[5] A. Sabir, "Sur une nouvelle méthode de mesure des charges d'espace dans les câbles haute tension", Ph. D. Dissertation, Université de Montpellier 2, Montpellier, France, 1991.

[6] E.Belgaroui, Y. Milk and A. Toureille,"Trapped space charge densites determination in a polyethylene conical connexion by the TSM method", Phys. Chem. News. 18 (2004) 68-77.

[7] K. Suzuki, Y. Tanaka, T. Takada, Y. Ohki, C. Takeya,"Space Charge Distribution Measurement in XLPE Cable for Detection of Water Tree Location”, Proc. CEIDP 1999, pp. 630-633, 1999.

[8] E.Belgaroui, H. Guermazi, S. Agnel, Y. Milk and A. Toureille, "a new numerical technique of electric field determination within dielectric materials plate and cable using the TSM method", Eur. Phys. J. AP 23, 63-71 (2003).

[9] N. Didon, S. Agnel, J. Castellon, P. Notingher, A. Toureille, J. Matallana, H. Janah, P. Mirebeau, R. Coelho, " Distribution du champ électrique sous haute tension continue et gradient de température dans le diélectrique des câbles extrudes", Journal of Electrostatics 64 (2006) 456-460.

[10] A. Cernomorcenco, P. Notingher Jr., "Application of the Thermal Step Method to Space Charge Measurements in Inhomogeneous Solid Insulating Structures: A Theoretical Approach", Appl. Phys. Lett., Vol. 93, pp. 1929031 to 3, 2008. 
Proc. of the Third Intl. Conf. on Advances in Mechanical and Automation Engineering - MAE 2015.

Copyright $(\subset$ Institute of Research Engineers and Doctors, USA .All rights reserved.

ISBN: 978-1-63248-080-4 doi: 10.15224/ 978-1-63248-080-4-115

[11] P. Notingher Jr., A. Toureille, S. Agnel, J. Castellon, "Determination of Electric Field and Space Charge in the Insulation of Power Cables with the Thermal Step Method and a New Mathematical Processing", IEEE Trans. Ind. App., Vol. 45, No. 1, pp. 67-74, 2009.

[12] P. Notingher Jr, A. Cernomorcenco, C. Stancu, P.V. Notingher, J. Castellon, S. Agnel and A. Toureille, "Determination of electric field in non homogeneous dielectric media with cylindrical geometry using the Thermal Step Method", SFE 2010, Montpellier, France, 30/08/201001/09/2010.

[13] A. Cherifi, “contribution à l'étude des charges d'espace dans les polymères isolants utilisés en HT: Améliorations de la méthode de l'onde thermique", thèse de doctorat, Université de Montpellier 2, Montpellier, France, 1993.

[14] J. Santana, "Mesures des charges d'espace de transport d'énergie électrique", thèse de doctorat, Université de Montpellier 2, Montpellier, France, 1994.

[15] A. Toureille, Mesures de charge d'espace par la méthode de l'onde thermique: différentes techniques de validation numérique et expérimentale, J. Electrostat. 32 (1994) 277-286.

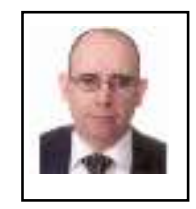

Youcef ZEBBOUDJ was born in Ighram (Akbou), Algeria. He received his Doctorate in Electrical Engineering in 1988 at the University P. et M. Curie (France). He is Professor at the University A Mira of Béjaia (Algeria). He is the director of the Laboratoire de Génie Electrique of the University A. Mira of Bejaia since 2000. His research interests are corona discharge and its applications in electrostatic precipitator, the charge of dielectric and the partial discharges in shielded power cable.

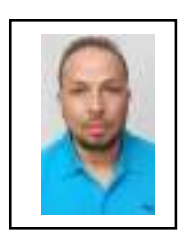

Abdelkrim LAIFAOUI is a teacher in Electrical Engineering Department since 2006. He joined the Laboratoire de Génie Electrique of the A. Mira University since 2003 as a member of the electrical discharge research group. He obtained his electrical engineering diploma electrical networks option in 2001 and achieved his magister thesis in Electrotechnics, high voltage option, in 2005 at A. Mira University of Bejaia (Algeria). His field of research is about solids insulators aging, electrical space charge and studying protective devices. He is author and coauthor of numerous papers presented in several national and international scientific conferences.

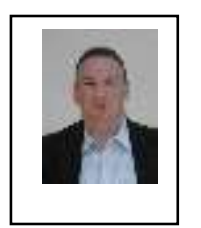

Jean-Michel REBOUL was born in Montpellier, France in 1972. He studied physics and heat transfer in the universities of Montpellier and Poitiers. In 1997, he joined the Laboratoire Universitaire des Sciences Appliquées de Cherbourg (LUSAC) of the Université de Caen Basse-Normandie for his Ph.D. on space charge measurement on dielectric films by thermal techniques. Since 2002, he is Maître de Conférences (assistant professor) in the Ecole d'Ingénieurs de Cherbourg (EIC). He teaches electrical engineering, heat transfer, sensors and actuators. His research fields are dielectric characterizations and electrical insulation studies.

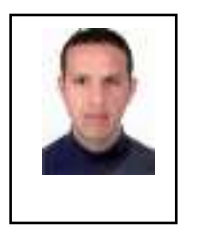

Hakim AITSAID was born in Bejaia,

Algeria, in 1982. He received the

Electrical Engeneering degree from Bejaia University of Science and Technology in 2009 and the Magister degree from Bejaia University of Science and Technology in 2011 discussing a thesis on effect of the humidity in electrostatic precipitators.

From 2010, he is a member of laboratory of Electrical Engineering of the University A. Mira of Bejaia. 